\title{
Correspondence
}

\section{NSF fleet vital for ocean science}

Your analysis of the long-term investment strategy of the US National Science Foundation (NSF) fails to recognize the extent to which the agency's academic-research fleet is one of the most vital elements of its oceanographic infrastructure (Nature 501, 461; 2013).

The increasing complexity of large-scale global programmes on climate and ocean science, such as CLIVAR, GEOTRACES and GeoPRISMS, calls for modern vessels that can host large research groups and that use sophisticated on-board sampling and processing equipment. These vessels are needed for operating state-ofthe-art observation systems, interpreting satellite data, and launching and recovering the gliders and autonomous underwater and aerial vehicles used by the ocean research community.

The replacement strategy that you criticize is in fact insufficient to replace a research fleet, the age and escalating costs of which mean that it is barely capable of meeting projected scientific requirements - even if all three planned regional research vessels are constructed over the coming decade.

It is difficult to provide infrastructure, which takes many years to design and build, with budgets that are unpredictable and constantly changing. Core science budgets should be kept separate from funding for the operation and maintenance of crucial research infrastructure, and not just from its construction. These are complementary rather than competing projects, and both need greater investment.

Properly informed, scientifically based policies and strategies will save the public much more money than would be saved by cutting costs on essential scientific infrastructure. Peter B. Ortner on behalf of the University-National Oceanographic Laboratory System, USA. portner@rsmas.miami.edu

\section{Appeal for funds to fight banana blight}

Mozambique's government has implemented quarantine measures to help control an outbreak in the country of a fungal pathogen that is ravaging banana plantations all over southeast Asia (see go.nature. com/1oiywc). To be effective, these efforts must be backed by prompt diagnosis and management of the disease.

The TR4 fungus (Fusarium oxysporum f. sp.cubense Tropical Race 4) is one of several genotypes that cause Fusarium wilt, or Panama disease. It can be swiftly identified by using molecular diagnostics, but plantation workers must first be able to recognize and rapidly report the early symptoms of infection.

To this end, Bioversity International, a non-profit research and training centre, and its regional partners are offering training in field expertise (see panamadisease.org and go.nature.com/y1y7br).

Governments and the banana industry must supply more funds if the disease is to be contained. The money will help to extend and consolidate educational and management initiatives, enable the gathering of comprehensive epidemiological data and stimulate research - for example, into fungus eradication or the development of resistant banana cultivars.

The costs will be negligible compared with the long-term cost to the livelihoods and food security of millions of people if the disease spreads.

Gert H. J. Kema Wageningen University \& Research Centre, the Netherlands. gert.kema@wur.nl Stephan Weise Bioversity International, Rome, Italy.

\section{Universities aid EU research mobility}

You suggest that universities are not doing enough to increase research mobility across Europe (Nature 502, 5; 2013). But at the European University Association (EUA) in Brussels, our evidence indicates that universities are in fact the main drivers towards a borderless European Research Area (ERA).

The EUA is one of the signatories of the European Commission's voluntary memoranda of understanding that seek to promote the ERA. Through contact and consultation with $85 \%$ of university respondents within our membership of some 850 institutions, we see that universities are making considerable efforts to advance ERA reforms.

For example, an EUA survey to be published in early 2014 shows that more than $80 \%$ of member universities already have institutional policies in place to promote gender equality - not $20 \%$, as you quote and as cited in the commission's ERA Progress Report 2013. These reforms are advancing steadily, despite financial and administrative constraints.

The European Commission could damage future research initiatives if it shakes a stick at non-complying countries, given that many institutions in those nations are contributing substantially to ERA objectives. Europe's universities could instead do with a few more carrots to impel their efforts. David J. Drewry EUA, Brussels, Belgium. david.drewry@hull.ac.uk

\section{African database for education schemes}

The severe shortage of trained scientists in Africa (see go.nature.com/gio8pu) has given rise to a variety of programmes and initiatives to recruit more students into science, technology, engineering and mathematics (STEM), and to encourage them to complete their education. A central database that collects and analyses data from all such enterprises is urgently needed to help coordinate their efforts, increase their effectiveness, make them more visible to the public and inform sponsors' funding decisions.

African science is also beset with systemic problems such as a lack of funding and laboratory equipment, and a pervasive lack of appreciation of the importance of science to a country's development (see, for example, V. Irikefe et al. Nature 474, 556-559; 2011).

Remedial initiatives across the continent include the creation of science and technology institutes, online science networks, science camps, mentoring programmes, scholarships and research fellowships.

The proposed database could be modelled on the US STEMconnector, which provides a comprehensive directory and analysis for more than 6,200 STEM programmes across the United States.

It is in the interest of African governments, universities and companies to step up and fund this database.

Fanuel Muindi Massachusetts Institute of Technology, Cambridge, USA. fmuindi@mit.edu Moytrayee Guha Harvard Medical School, Boston, USA.

CONTRIBUTIONS

Correspondence may be submitted to correspondence@nature. com after consulting the author guidelines at http://go.nature.com/ cmchno. Alternatively, readers may comment online: www.nature.com/ nature. 